\title{
TWO-DIMENSIONAL WIND TUNNEL MEASUREMENT CORRECTIONS BY THE SINGULARITY METHOD
}

\author{
Taha Ahmed Abdullah, Zlatko Petrović, Zoran Stefanović, Ivan Kostić, Jovan Isaković
}

Original scientific paper

The correction method for pressure coefficient distribution around an airfoil is developed for the purpose of the postprocessing of wind tunnel data, obtained from the model pressure measurements. Pressure coefficient distribution around the airfoil, directly obtained by wind tunnel measurements, is corrected numerically in order to compensate for the interference effects of the wind tunnel test section walls. In this paper, the airfoil NACA0012 is approximated by linear vortex segments, which are then mirrored using sufficient number of images with respect to the ceiling and the floor of the test section, to model the flow pattern around an airfoil in the wind tunnel test section with solid walls. Flow calculations, both with the tunnel wall presence and in the free stream, are then performed. The numerically obtained pressure coefficient difference between these two cases should be superimposed to the pressure coefficient distribution measured in the wind tunnel, for the same nominal airflow parameters and angle of attack, at the corresponding points, resulting in the corrected experimental pressure coefficient distribution. The values of corrections generally increase with the reduction of the wind tunnel test section relative height. The paper is focused on the verification of lift curve slope corrections, where very good agreements have been obtained with several well-known classical correction methods.

Keywords: pressure coefficient; singularity method; vortex distribution; wall interference; wind tunnel corrections

Korekcije rezultata dvodimenzijskih aerotunelskih mjerenja metodom singulariteta

Izvorni znanstveni članak

Razvijena je metoda za korigiranje raspodjele koeficijenta pritiska oko aeroprofila u cilju obrade rezultata dobivenih mjerenjima pritiska na modelu $\mathrm{u}$ aerotunelu. Zbog utjecaja interferencije sa zidovima radnog dijela aerotunela, raspodjela koeficijenta pritiska neposredno dobivena mjerenjima korigira se numerički. U ovom radu, aeroprofil NACA 0012 aproksimiran je linijskim vrtložnim segmentima, koji se preslikavaju kao lik u ogledalu dovoljno puta u odnosu na položaje poda i plafon radnog dijela, da bi se modeliralo strujanje oko aeroprofila u neporoznom radnom dijelu aerotunela. Proračun se zatim vrši kako za slučaj strujanja sa prisustvom zidova, tako i za opstrujavanje u slobodnoj atmosferi. Razlika u numerički određenoj raspodjeli koeficijenata pritiska za ova dva slučaja se u odgovarajućim točkama superponira sa raspodjelom pritisaka izmjerenom u aerotunelu, pri istim nominalnim uslovima strujanja i napadnom uglu, čime se dobija korigirana eksperimentalna raspodjela pritisaka. Koeficijent uzgona se zatim izračunava iz tako korigirane raspodjele koeficijenata pritiska. Vrijednosti korekcija generalno rastu sa smanjenjem relativne visine radnog dijela aerotunela. Rad je fokusiran na verifikaciju faktora korekcije gradijenta uzgona, gdje su vrlo dobra poklapanja dobijena u usporedbi s nekoliko poznatih klasičnih metoda korekcije.

Ključne riječi: aerotunelske korekcije; interferencija zidova; koeficijent tlaka; metoda singulariteta; raspodjela vrtloga

\section{Introduction}

Airfoils are cross-sectional shapes applied in wing forming and design, whose aerodynamic characteristics remarkably influence the flying characteristics of an aircraft. Airfoil characteristics are defined as aerodynamic parameters of a wing of an infinite span, where the flow is purely two-dimensional (2D), since there is no influence of secondary wing tip flow, due to which the real - finite span (i.e. finite aspect ratio) wings are exposed to 3D flow patterns. Namely, due to the pressure difference between lower and upper wing surface, by which lift is generated, the flow on tips "leaks" from lower to upper side around them, pushing the flow on upper wing surface towards, and on lower side away from the wing root. Once we know aerodynamic characteristics of airfoils that will be used in wing design, characteristics of an actual finite aspect ratio wing can nowadays be calculated by many different available methods.

Airfoil characteristics are usually determined in wind tunnels, or at least confirmed by wind tunnels, if computational methods had been used in airfoil design and analysis. The 2D flow in wind tunnels is simulated by placing a rectangular wing model with constant airfoil between the test section side walls, or between boundary plates, which physically prevent secondary flow around the model's tips. Results obtained in the wind tunnels considering 2D airfoil, but also 3D wing and complete aircraft tests, are not identical to those that would be obtained in free stream (atmospheric flight), not only because it is hard to maintain the same Reynolds and Mach number, but also because it is difficult to maintain the free-stream turbulence level, and roughness characteristics. Besides that, the wind tunnel test section is of limited size and has a boundary layer attached to walls, slightly affecting the simulated two-dimensional flow field around airfoil models. Corrections of experimental results due to finite test section size are the subject of this paper. Wind tunnel walls affect the complete flow field around the airfoil, considering the restricted flow curvature in front and behind the airfoil, speed and pressure distributions, etc. It is assumed in this paper that the floor and ceiling of the test section are far enough, so that the required corrections of the test results are small enough, and can be added or subtracted directly from the measured flow quantities. In 2D analyses, the most relevant perturbances generated both by the airfoil and by the walls are on the flow characteristics in longitudinal and normal directions, thus the influence of side walls can be neglected without any substantial penalties on the results aimed for practical applications.

In the sense of computational analyses, the difference in computed values of flow parameters for an airfoil first with, and then without wind tunnel walls, is combined with pressure distributions measured in wind tunnel, in order to obtain corrected experimental results, that would correspond to free stream conditions (these values can then be used as inputs in wing design). 
In here applied numerical calculations, the airfoil is represented by appropriate singularities that generate induced speeds which, when superimposed with undisturbed flowfield, simulate airflow parameters that correspond to free stream conditions. The simplest way to model wind tunnel upper and lower solid wall influence is to add one airfoil above, and one below the actual airfoil like "images" in the mirror, where "mirrors" are placed at wind tunnel wall positions, and images are at the same distances from them as actual airfoil. Theoretically, the most accurate results are obtained when number of images above and below the airfoil tends to infinity. In practical calculations, this number is finite, after which any further images generate no practical influence. The custom written software, used for here presented calculations, is based on this general approach. It is clear that the same software can simulate the free stream conditions, simply by setting the number of mirrored images to zero.

\section{Overview of different correction method approaches}

In reference [1], the computational solution of the flow about airfoil is used to calculate the necessary curvature of the adaptive wall which will result in the same pressure distribution over the wall as the distribution obtained from calculations. The same principal idea using adaptive slots is described in [2]. Sawada in his paper [3] used horse-shoe vortex distribution over a wing to calculate interference effects of ventilated wind tunnel walls. Measured pressure distribution over walls is used as a boundary condition for the potential flow solution within test section. Mokry [4] used fast Fourier transformation to solve Laplace equation in twodimensional wind tunnel test section, using experimental wind tunnel wall pressure distributions combined with a doublet - vortex approximation of the airfoil shape as boundary conditions to solve Laplace's equation. The intensity of the vortex is adjusted to the measured lift coefficient, while corrections are made on angle of attack and airspeed due to buoyancy effect. Correction is taken from the results obtained at the position of the vortex doublet singularity. The wall correction method of Kuppers [5] is based on measured pressure distribution on the tunnel walls to solve Laplaces equation. This method combines theoretical calculated boundary conditions with experimental test data. The results of this method are compared with the measured and corrected data, and the data from free flight. The calculation of wind tunnel wall interference is based on the solution of Greens integral. Mokry [6] used first order doublet-panel method to correct Mach number and angle of attack obtained by measurements in the test section of the wind tunnel with perforated walls. The measured static pressure over walls and measured forces on the model are applied as boundary conditions. The procedure by Thomas and Zeki [7] utilizes measurements of the wall pressure distribution to develop a flow field solution based on the method of singularities. This flow field solution is then imposed as a pressure boundary condition in a CFD simulation of the internal flow field. The singularity method is applied for two and three dimensional wind tunnels with porous walls. Ashil and Week [8] used the Greens theorem to solve Laplace's equation to represent a potential flow field. The wall interferences are calculated for two and three dimensional model by measuring static pressures as boundary conditions on the walls. Holt and Hant [9] evaluated subsonic wall interference effects in both two and three dimensional model by panelling the roof and ceiling with linear distribution of vorticity. Certain interesting new approaches in wind tunnel corrections can be found, for example in paper of Horsten and Veldhuis [10], which presents a method based on uncorrected wind tunnel measurements and fast calculation techniques.

In this paper, the vortex panels with linear vorticity strength variation are used to approximate the airfoil shape in the test section of a wind tunnel. These vortex panels are repeatedly mirrored with respect to the ceiling and the floor of the test section, thus simulating real flow conditions in test section, in which streamlines must be tangent to the wind tunnel walls. Pressure distribution over the airfoil is calculated both in the presence of the walls (simulated by images), and without them (free stream). The difference in pressure coefficients between free-stream numerical solution and numerical solution with walls is calculated, and superimposed to uncorrected pressure distributions, measured in an actual wind tunnel. Pressure distribution correction approach implicitly corrects the lift coefficient, as well as the moment coefficient. Buoyancy effect is contained in pressure coefficient correction, so measured speed is true speed. Also, measured angle of attack is true angle of attack. Such correction model is applicable as long as the assumption of inviscid flow can be applied with sufficient accuracy for practical purposes (massive flow separations at high angles of attack cannot be treated this way).

In this paper, the corrections are focused on the lift coefficient evaluations. The calculations have been performed for symmetrical NACA 0012 airfoil, used for many years as standard "test" airfoil for the verification of both the computational models, and experimental facilities.

Also, here presented method, based on the image mirroring above and below the wind tunnel airfoil, confines the corrections to the solid walls condition. The planned future work should upgrade this model with an ability to perform corrections for lift and moment coefficients for wind tunnels with perforated walls as well. The key difference between this model and most of the previously developed procedures is that it applies corrections to the pressure coefficient, while keeping the same nominal speed (i.e. Mach number) and angle of attack

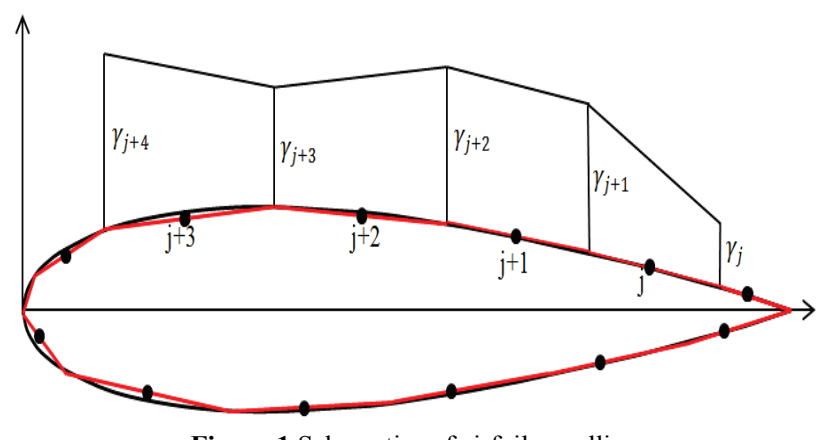

Figure 1 Schematics of airfoil panelling 


\section{Fundamental assumptions}

The following assumptions are adopted in this paper:

1) The flow about a two-dimensional airfoil is inviscid and irrotational.

2) The airfoil is represented by a sufficiently large number of linear vortex panels (Fig. 1).

3) The air flow is subsonic.

4) Corrections are small, and can be applied linearly.

5) Three-dimensional effects are negligible.

\subsection{Governing equations}

The first assumption replaces Navier-Stokes equations by potential flow equation:

$\beta^{2} \frac{\partial^{2} \hat{\phi}}{\partial \hat{x}^{2}}+\frac{\partial^{2} \hat{\phi}}{\partial \hat{y}^{2}}=0$.

Compressibility correction parameter is defined as:

$\beta=\sqrt{1-M^{2}}$

where $M$ is the free stream Mach number, and the small disturbance perturbation velocity potential $\hat{\phi}$ has been defined as follows:

$\hat{\phi}=U_{\infty} x+V_{\infty} y+\phi$

Transforming $\hat{\phi}$ and $(\hat{x}, \hat{y})$ by equation:

$(x, y)=(\hat{x}, \beta \hat{y})$,

we obtain $\Delta \phi=0$, where Laplace operator is:

$\Delta=\frac{\partial^{2}}{\partial \hat{x}^{2}}+\frac{\partial^{2}}{\partial \hat{y}^{2}}$.

This equation is solved for free-stream conditions, and for airfoil in the wind tunnel test section, using the superposition principle of singular solutions, since Laplace equation is linear. Any combination of singular solutions is also the solution of the Laplace's equation. Our task here is to select arbitrary constants for singularity solutions that, besides satisfying the Laplace's equation, also satisfy boundary conditions.

\subsection{Boundary conditions}

On both airfoil and wind tunnel walls, the normal component of the velocity at any point of the solid surface must be equal to zero. This requirement is achieved by:

1) Establishing an imaging system of the airfoil, represented by linear vortex segments, with the respect to the floor and ceiling of the wind tunnel test section. This imaging system ensures simulation of the real flow-field streamlines, which are parallel to the floor and the ceiling of the test section.
2) Posting the condition that the normal component of the velocities over the solid surface of the airfoil (i.e. on the control points of the panels) satisfy the following condition:

$\boldsymbol{V}_{i} \cdot \overrightarrow{\boldsymbol{n}}_{i}=0$

Subscript $i$ indicates a control point whose coordinates are $x_{c_{i}}, y_{c_{i}}$.

3) To ensure that velocity at the trailing edge is finite, the Kutta condition must be satisfied at the trailing edge.

\section{Induced velocities}

\subsection{Two-dimensional vortex point}

Consider a point vortex with strength $\Gamma$ located at $\left(x_{0}, y_{0}\right)$ as shown in Fig. 2. The induced velocity components by this vortex at point $P(x, y)$ are:

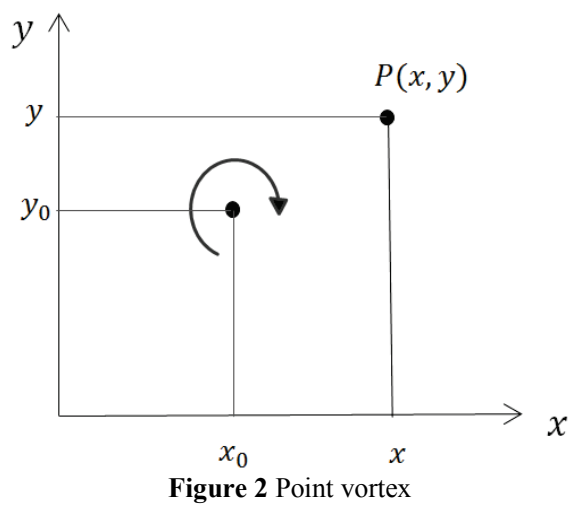

$u=\frac{\partial \phi}{\partial x}=\frac{\Gamma}{2 \pi} \frac{\left(y-y_{0}\right)}{\left(x-x_{0}\right)^{2}+\left(y-y_{0}\right)^{2}}$,

$v=\frac{\partial \phi}{\partial y}=\frac{\Gamma}{2 \pi} \frac{\left(x-x_{0}\right)}{\left(x-x_{0}\right)^{2}+\left(y-y_{0}\right)^{2}}$.

\subsection{General linear vortex distribution}

Velocity induced at some arbitrary point $(x, y)$ by vorticity with linear strength variation along the segment (see Fig. 3) is calculated by applying the superposition principle. By this principle, contribution of all vortices $\gamma\left(x_{0}\right) \mathrm{d} x_{0}$ along vortex segment placed between $x_{1}$ and $x_{2}$ are added to obtain:

$u=\frac{1}{2 \pi} \int_{x_{1}}^{x_{2}} \gamma\left(x_{0}\right) \frac{x_{0} y}{\left(x-x_{0}\right)^{2}+y^{2}} \mathrm{~d} x_{0}$,

$v=-\frac{1}{2 \pi} \int_{x_{1}}^{x_{2}} \gamma\left(x_{0}\right) \frac{x_{0}\left(x-x_{0}\right)}{\left(x-x_{0}\right)^{2}+y^{2}} \mathrm{~d} x_{0}$.

These velocity components are expressed in local coordinate system. To use these expressions for arbitrary position of the vortex segment, it is necessary to transform the coordinates of the end points of the vortex and coordinates of the arbitrary point $(x, y)$ to the coordinate system fixed to segment. Vorticity distribution $\gamma\left(x_{0}\right)$ is determined by vorticity strengths $\gamma_{1}$ and $\gamma_{2}$ at 
segment's end points. Their magnitude is determined from boundary conditions (see Eq. (6)).

$\gamma\left(x_{0}\right)=\gamma_{1}+\Delta\left(x_{0}-x_{1}\right)$

where $\Delta=\frac{\gamma_{2}-\gamma_{1}}{x_{2}-x_{1}}$.

Integration of expressions for $u$ and $v$ gives induced velocity by vortex segment at any point $(x, y)$ in the segment-fixed coordinate system:

$u=\frac{\gamma_{1}}{2 \pi}\left(\theta_{2}-\theta_{1}\right)+\frac{\Delta}{2 \pi}\left[y \ln \frac{r_{1}}{r_{2}}-x\left(\theta_{2}-\theta_{1}\right)\right]$,

$v=-\frac{\gamma_{1}}{2 \pi} \ln \frac{r_{1}}{r_{2}}-\frac{\Delta}{2 \pi}\left[x \ln \frac{r_{1}}{r_{2}}+\left(x_{1}-x_{2}\right)+y\left(\theta_{2}-\theta_{1}\right)\right]$.

Angles $\theta_{1}$ and $\theta_{2}$, as well as $r_{1}$ and $r_{2}$, are shown in Fig. 3.

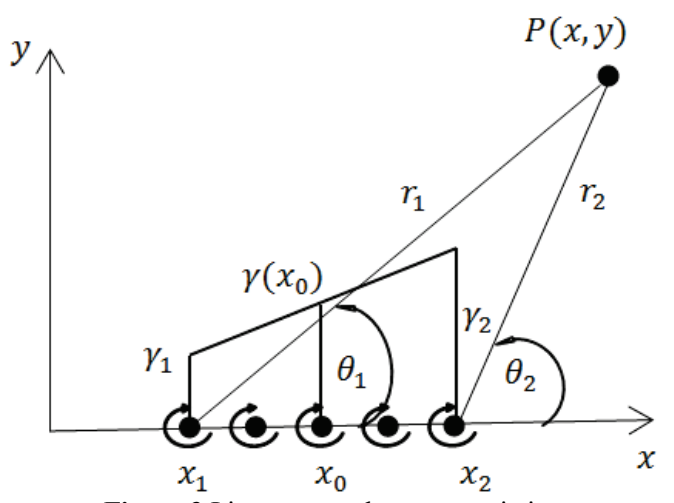

Figure 3 Linear strength vortex variation

\subsection{Linear vortex distribution with image}

In two dimensions, the solid wall boundary condition can be satisfied on the upper and lower walls by generating a column of airfoil images, represented by their vortex segments, mirrored both above and below the test section. Theoretically, the number of images is infinite. In Fig. 4 the segment of linear vortex strength distribution in the test section is mirrored by an infinite number of its symmetric images with respect to the ceiling and the floor of the test section. All images as well as an original segment on the airfoil contribute to the induced velocities. The $n^{\text {th }}$ image of the vortex segment is placed between points $x_{1}$ and $x_{2}$ in global coordinate system, as well as a segment in the test section. The local coordinate system is fixed to this segment image, with the $x$-axis passing through $x_{1}$ and $x_{2}$.

Velocity components induced at point $(x, y)$ in the local coordinate system are calculated by:

$$
\begin{aligned}
& u_{n}=(-1)^{n}\left\{\frac{\gamma_{1}}{2 \pi}+\frac{\Delta}{2 \pi}\left[y \ln \frac{r_{1_{n}}}{r_{2 n}}-x\left(\theta_{2 n}-\theta_{1 n}\right)\right]\right\}, \\
& v_{n}=(-1)^{n}\left\{-\frac{\gamma_{1}}{2 \pi}-\frac{\Delta}{2 \pi}\left[x \ln \frac{r_{1 n}}{r_{2 n}}\left(x_{1}-x_{2}\right)+y\left(\theta_{2 n}-\theta_{1 n}\right)\right]\right\},
\end{aligned}
$$

where $u_{n}$ and $v_{n}$ represent components of induced velocity at an arbitrary point $(x, y)$ in the local coordinate system of the $n^{\text {th }}$ segment image.
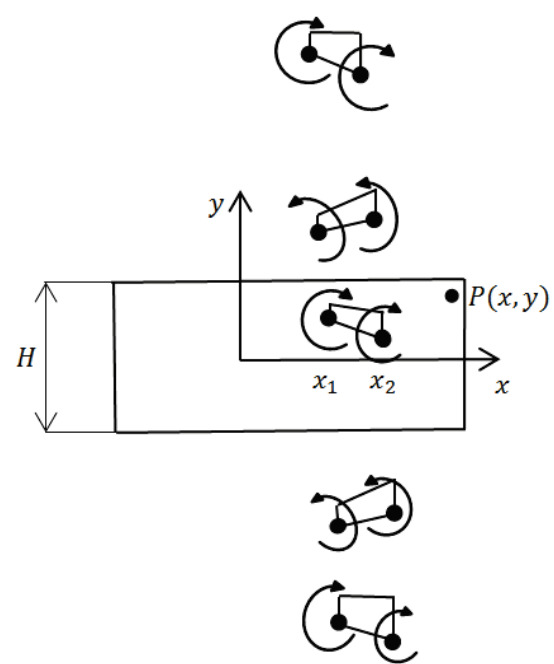

Figure 4 The system of images

\section{Numerical solution of the flow about the airfoil}

In the Eqs. (14) and (15) the subscripts 1 and 2 refer to first and last point of a panel, globally defined by points numerated as $j$ and $j+1$ respectively. The airfoil NACA 0012 in this work is given with $N+1$ pairs of $(x$, $y$ ) coordinates ordered counterclockwise, starting from the trailing edge of the airfoil. The shape of the airfoil is approximated by $N$ panels connecting these $N+1$ point coordinates of the airfoil. In expressions for induced velocities, $\gamma_{1}$ and $\gamma_{2}$ are local parameters, unique for each panel. These coefficients are used to model vortex strength variation over the panel. If the strength of $\gamma$ at the beginning of each panel is set equal to the strength of the vortex at the end point of the previous panel, the continuous vortex distribution is obtained.

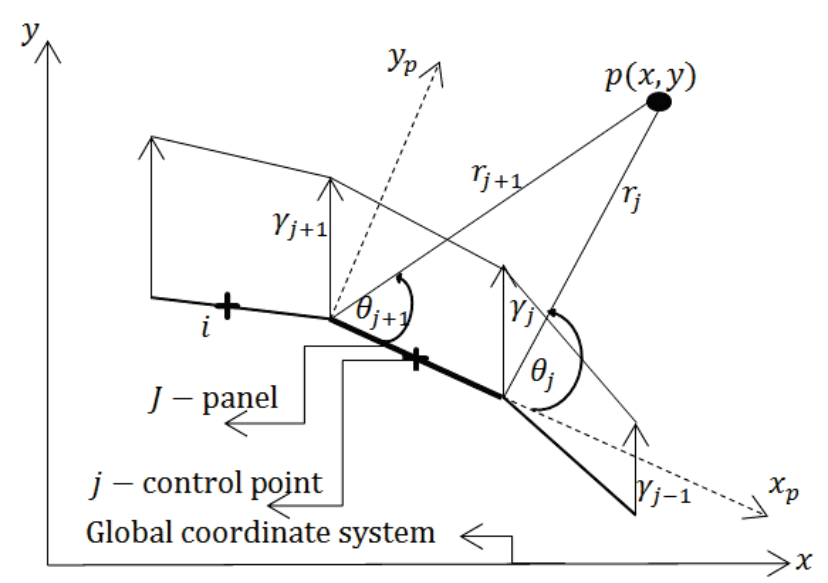

Figure 5 Nomenclature for a linear-strength vortex element

The numerical procedure should determine all vortices $\left(\gamma_{j}, \gamma_{j+1}, \ldots\right)$ at the end points of the panels, see Fig. 5. If the airfoil shape is approximated by $N$ distributed vortex panels, then the number of unknown parameters is equal to the number of points which define vortex segments, i.e. $N+1$, one greater than number of 
panels. To apply Eqs. (12) to (15), subscripts 1 and 2 should be replaced by $j$ and $j+1$ respectively.

The induced velocity components in local coordinate system of the panel at $i^{\text {th }}$ control point by $n^{\text {th }}$ image is expressed in terms of the panel-edge vorticity strengths $\gamma_{j}$ and $\gamma_{j+1}$. This way, Eqs. (14) and (15) become:

$$
\begin{aligned}
u_{i j n}= & (-1)^{n}\left\{\frac{\gamma_{j}}{2 \pi}\left(\theta_{(j+1)_{n}}-\theta_{j_{n}}\right)+\frac{\left(\gamma_{j+1}-\gamma_{j}\right)}{2 \pi\left(x_{j+1}-x_{j}\right)} .\right. \\
& \left.\cdot\left[y_{i} \ln \frac{r_{j_{n}}}{r_{(j+1)_{n}}}-x_{i}\left(\theta_{(j+1)_{n}}-\theta_{j_{n}}\right)\right]\right\}, \\
v_{i j n}= & (-1)^{n}\left\{-\frac{\gamma_{j}}{2 \pi} \ln \frac{r_{j_{n}}}{r_{(j+1)_{n}}}-\frac{\left(\gamma_{j+1}-\gamma_{j}\right)}{2 \pi\left(x_{j+1}-x_{j}\right)} \cdot\right. \\
& \left.\cdot\left[x_{i} \ln \frac{r_{j_{n}}}{r_{(j+1)_{n}}}+\left(x_{j}-x_{j+1}\right)+y_{i}\left(\theta_{(j+1)_{n}}-\theta_{j_{n}}\right)\right]\right\} .
\end{aligned}
$$

Control point coordinates with respect to vorticity segment $J$ are transformed in segment fixed coordinate system by Eqs. (18) and (19):

$$
\begin{aligned}
& X_{i J_{n}}=\left(x_{c_{i}}-x_{j}\right) \cos \alpha_{j n}+\left(y_{c_{i}}-y_{j_{n}}\right) \sin \alpha_{j n}, \\
& Y_{i J_{n}}=\left(y_{c_{i}}-y_{j_{n}}\right) \cos \alpha_{j n}-\left(x_{c_{i}}-x_{j}\right) \sin \alpha_{j n},
\end{aligned}
$$

where $\left(x_{c_{i}}, y_{c_{i}}\right)$ are global coordinates of the control point, $\left(x_{j}, y_{j_{n}}\right)$ are global coordinates of the first point of the $n^{\text {th }}$ segment $J$ image, while $\left(X_{i J_{n}}, Y_{i J_{n}}\right)$ are local coordinates of the control point, as viewed from the local coordinate system fixed to segment $J$ (see Fig. 5). Local coordinates of the starting points are $(0,0)$, while the local coordinates of the end points of the segment are given as shown in Eqs. (20) and (21).

$$
\begin{aligned}
& X_{(j+1)_{n}}=\left(x_{j+1}-x_{j}\right) \cos \alpha_{j n}+\left(y_{(j+1)_{n}}-x_{j_{n}}\right) \sin \alpha_{j n}, \\
& Y_{(j+1)_{n}}=\left(y_{(j+1)_{n}}-y_{j_{n}}\right) \cos \alpha_{j n}-\left(x_{j+1}-x_{j}\right) \sin \alpha_{j n} .
\end{aligned}
$$
is $\alpha_{j n}$.

The slope of the segment with respect to global $x$-axis

The distances between the control point and the end points of the segment are: $R_{i j_{n}}, R_{(i j+1)_{n}}$.

Angles between segments and the lines connecting end of the segment with control point are given as:

$$
\theta_{i j_{n}}, \theta_{(i j+1)_{n}} .
$$

It is necessary to separate contributions to the induced velocity at control points into parts influenced only by end segment vorticities. Eqs. (16) and (17) can be divided into a portion of velocity influenced by $\gamma_{j}$ and a portion of velocity influenced by $\gamma_{j+1}$. The superscripts ()$^{j}$ and ()$^{j+1}$ represent the contribution of the beginning and the contribution of the ending vorticity strength.

$$
\begin{aligned}
& u_{i_{n}}^{j}=\gamma_{j}(-1)^{n} \frac{1}{2 \pi}\left\{\left[\left(\theta_{(j+1)_{n}}-\theta_{j_{n}}\right)+\frac{Y_{i J_{n}}}{X_{(j+1)_{n}}} \ln \frac{R_{j_{n}}}{R_{(j+1)_{n}}}-\right.\right. \\
& \left.\left.-\frac{X_{i J_{n}}}{X_{(j+1)_{n}}}\left(\theta_{(j+1)_{n}}-\theta_{j_{n}}\right)\right]\right\} \text {, } \\
& u_{i_{n}}^{j+1}=\gamma_{j+1}(-1)^{n} \frac{1}{2 \pi}\left\{\left[\frac{X_{i J_{n}}}{X_{(j+1)_{n}}}\left(\theta_{(j+1)_{n}}-\theta_{j_{n}}\right)-\right.\right. \\
& \left.\left.-\frac{Y_{i J_{n}}}{X_{(j+1)_{n}}} \ln \frac{R_{j_{n}}}{R_{(j+1)_{n}}}\right]\right\} \text {, } \\
& v_{i_{n}}^{j}=\gamma_{j}(-1)^{n} \frac{1}{2 \pi}\left\{\left[\ln \frac{R_{j_{n}}}{R_{(j+1)_{n}}}\left(\frac{X_{i J_{n}}}{X_{(j+1)_{n}}}-1\right)-1+\right.\right. \\
& \left.\left.+\frac{Y_{i J_{n}}}{X_{(j+1)_{n}}}\left(\theta_{(j+1)_{n}}-\theta_{j_{n}}\right)\right]\right\} \\
& v_{i_{n}}^{j+1}=\gamma_{j+1}(-1)^{n} \frac{1}{2 \pi}\left\{\left[1-\frac{X_{i J_{n}}}{X_{(j+1)_{n}}} \ln \frac{R_{j_{n}}}{R_{(j+1)_{n}}}-\right.\right. \\
& \left.\left.-\frac{Y_{i J_{n}}}{X_{(j+1)_{n}}}\left(\theta_{(j+1)_{n}}-\theta_{j_{n}}\right)\right]\right\} \text {, }
\end{aligned}
$$

where $u_{i_{n}}^{j}, u_{i_{n}}^{j+1}, v_{i_{n}}^{j}$ and $v_{i_{n}}^{j+1}$ represent the induced velocity components influenced by the vorticity strengths at the beginning and at the end of each segment. The calculations of the Eqs. (22), (23), (24) and (25) are based on the assumption that $\gamma_{j}=1$ and $\gamma_{j+1}=0$. The induced velocity at any point in the flow field in local (segment fixed) coordinate system is:

$u_{i J_{n}}=u_{i_{n}}^{j}+u_{i_{n}}^{j+1}$

$v_{i J_{n}}=v_{i_{n}}^{j}+v_{i_{n}}^{j+1}$.

The Eqs. (22), (23), (24) and (25) can be arranged to separate vorticity strengths $\gamma_{j}$ and $\gamma_{j+1}$.

Induced velocity components, calculated in segment fixed coordinate system, have to be transformed back into airfoil coordinate system, and summed up to determine induced velocity at a control point $\left(x_{c_{i}}, y_{c_{i}}\right)$ by the vorticity segment $J$ :

$u_{i J}=\sum_{n=-k}^{n=k} u_{i J_{n}} \cos \alpha_{j n}-\sum_{n=-k}^{n=k} v_{i J_{n}} \sin \alpha_{j n}$,
$v_{i J}=\sum_{n=-k}^{n=k} u_{i J_{n}} \sin \alpha_{j n}+\sum_{n=-k}^{n=k} v_{i J_{n}} \cos \alpha_{j n}$,

where $k$ determines the number of images used in the calculation. Number $k$ is determined in such a way that the contribution of the first neglected image, which is too far to generate any practical influence to the relative velocity, is less than the specified small number $\varepsilon$, defined as: 
$\left|\frac{v_{n}}{v_{0}}\right|<\varepsilon$

The $v_{n}$ is velocity induced by the $n^{\text {th }}$ image of the vorticity segment, while $v_{0}$ is velocity induced by vorticity segment in the wind tunnel test section. Components of induced velocity in global coordinate system at $(x, y)$ point in the flow field are obtained by transforming local induced velocity components, due to vortex segment between points $j$ and $j+1$, according to:

$u_{i j}=\sum_{n=-k}^{n=k}\left(c_{i j_{n}} \cdot \gamma_{j}+e_{i j_{n}} \cdot \gamma_{j+1}\right) \cos \alpha_{j n}-$

$-\sum_{n=-k}^{n=k}\left(w_{i j_{n}} \cdot \gamma_{j}+z_{i j_{n}} \cdot \gamma_{j+1}\right) \sin \alpha_{j n}$,

$v_{i j}=\sum_{n=-k}^{n=k}\left(c_{i j_{n}} \cdot \gamma_{j}+e_{i j_{n}} \cdot \gamma_{j+1}\right) \sin \alpha_{j n}+$

$+\sum_{n=-k}^{n=k}\left(w_{i j_{n}} \cdot \gamma_{j}+z_{i j_{n}} \cdot \gamma_{j+1}\right) \cos \alpha_{j n}$. form:

Eq. (30) after rearrangement can be written in the

$u_{i j}=a_{i j} \cdot \gamma_{j}+b_{i j} \cdot \gamma_{j+1}$.

Similarly for eq. (31):

$v_{i j}=k_{i j} \cdot \gamma_{j}+s_{i j} \cdot \gamma_{j+1} \cdot$

Since vorticity strength $\gamma_{j}$ is shared by two neighbouring segments $J-1$ and $J$, it is necessary to group contributions of each end vorticity. Only first and last points are not shared by two vorticity segments. Components of induced velocity due to vorticity strength $\gamma_{j}$ are given by the Eqs. (34) and (35):

$u_{i}^{j, j-1}=\left(a_{i j}+b_{i, j-1}\right) \gamma_{j}=A_{i j} \cdot \gamma_{j}$

$A_{i j}=\left\{\begin{array}{cc}a_{i 1} & j=1 \\ a_{i j}+b_{i, j-1} & j=2 \ldots N \\ b_{i j} & j=N+1\end{array}\right\}$.

where the coefficients $a_{i 1}$ and $b_{i j}$ represent the coefficients of first and last segment.

$v_{i}^{j, j-1}=\left(k_{i j}+s_{i, j-1}\right) \gamma_{j}=B_{i j} \cdot \gamma_{j}$,

$B_{i j}=\left\{\begin{array}{cc}k_{i 1} & j=1 \\ k_{i j}+s_{i, j-1} & j=2 \ldots . N \\ s_{i j} & j=N+1\end{array}\right\}$.
Total velocity at a control point $\left(x_{c_{i}}, y_{c_{i}}\right)$ is obtained when all contributions are summed up:

$u_{i}=\sum_{j=1}^{N+1}\left(A_{i j} \cdot \gamma_{j}\right)+U_{\infty}$,

$v_{i}=\sum_{j=1}^{N+1}\left(B_{i j} \cdot \gamma_{j}\right)+V_{\infty}$.

Boundary conditions require that the normal velocity component to the airfoil surface at arbitrary control point $i$ is equal to zero:

$\overrightarrow{\boldsymbol{V}}_{i} \cdot \overrightarrow{\boldsymbol{n}}_{i}=u_{i} n_{x_{i}}+v_{i} n_{y_{i}}=0$.

Since the control point is defined in the middle of the segment, there are $N$ segments and thus $N$ conditions. Additional necessary condition is obtained from Kutta condition:

$\gamma_{1}+\gamma_{N+1}=0$

The system of equations is then solved to determine the coefficients of linear vortex strength panels.

Now, as the vorticity strengths $\gamma_{j}$ are known for all panels, then the induced velocity at each control point can be easily calculated by Eqs. (26) and (27). The pressure and lift coefficients can be calculated.

\section{The general correction procedure}

The calculations are performed by the custom written Fortran 90 computer code, based on the previously described method. Numerical solutions of the flow about NACA 0012 airfoil for the simulated free flight case, and for the simulated flow around the same airfoil in the test section under the same nominal flow conditions (Mach number and angle of attack) are calculated, and pressure distributions for both cases are obtained. The pressure coefficient differences $\Delta c_{p_{i}}$ at the corresponding points, between solutions for the flow in the test section and in free atmosphere, are defined as:

$\Delta c_{p_{i}}=c_{p_{i}}^{N}-c_{p_{\infty i}}^{N}$

According to here presented calculation model, the corrections of the "raw" wind tunnel pressure coefficient distribution should be performed by subtracting the so defined $\Delta c_{p_{i}}$ from the values obtained by wind tunnel measurements, at the same corresponding positions:

$c_{p_{i}}^{\text {corr }}=c_{p_{i}}^{\text {meas }}-\Delta c_{p_{i}}$

In operational use, the numerically obtained pressure differences are interpolated for the positions of pressure holes on the actual experimental model. Notation used in previous equations is: 
- $\quad c_{p_{i}}^{N}$ is the numerical solution for pressure coefficient distribution about airfoil in the test section;

- $c_{p_{\infty i}}^{N}$ is the numerical solution for pressure coefficient distribution about airfoil in free stream;

- $c_{p_{i}}^{\text {corr }}$ is the corrected experimental pressure coefficient distribution about the airfoil, that would correspond to the free stream airflow;

- $\quad c_{p_{i}}^{\text {meas }}$ is the pressure coefficient distribution about the airfoil, measured in the wind tunnel.

- $\Delta c_{p_{i}}$ pressure coefficient differences at the corresponding points, between numerical solutions for the flow in the test section and in free atmosphere.

The values of the lift coefficients are obtained by numerical integration of the pressure coefficient distributions.

\section{Results and discussion}

Results of the here presented calculation model will be compared with some standard correction procedures, widely used in the past. Since they were initially derived for low speed tests, the Mach number $M=0,15$ is applied at this time, and numerical corrections are calculated for angles of attack of $\alpha=2^{\circ}$ and $\alpha=6^{\circ}$.

The lift coefficient correction factor $K_{C_{L}}$ represents the ratio between the lift coefficient in free stream, and the lift coefficient in the tunnel test section:

$K_{C_{L}}=\frac{C_{L \text { free }}}{C_{L \text { tun }}}$

The angle of attack correction in here applied numerical model is zero (defined by the concept of the model itself), meaning that the corrected lift coefficient applies for the same angle of attack as in the wind tunnel. On the other hand, in classical methods, angle of attack correction is also applied, where the correction factor $K_{\alpha}$ for angle of attack is:

$K_{\alpha}=\frac{\alpha_{\text {free }}}{\alpha_{\text {tun }}}$.

Because of that, comparisons between the numerical model and classical methods must be done using the lift curve slope correction factor:

$K_{a}=\frac{K_{C_{L}}}{K_{\alpha}}$,

which is the ratio between the lift coefficient and angle of attack correction factors.

For the purpose of verification, the relative test section heights $h=3,4,5$ and 6 have been applied, where $h$ represents the ratio between the test section height and model chord length. Numerically obtained results and corrections are presented in Tabs. 1 and 2, and in Figs. 6 and 7.

From [11] and [12], the free stream lift coefficients for NACA 0012 airfoil, for angles of attack of $\alpha=2^{\circ}$ and $\alpha=6^{\circ}$, are $C_{L} \approx 0,22$ and $C_{L} \approx 0,66$, respectively.

Table 1 Numerically obtained correction parameters, $\alpha=2^{\circ}, M=0,15$

\begin{tabular}{|c|c|c|c|c|}
\hline & $h=3$ & $h=4$ & $h=5$ & $h=6$ \\
\hline$C_{L \text { free }}$ & 0,2390 & 0,2390 & 0,2390 & 0,2390 \\
\hline$C_{L \text { tun }}$ & 0,2539 & 0,2477 & 0,2445 & 0,2426 \\
\hline$K_{C_{L}}$ & 0,9413 & 0,9649 & 0,9776 & 0,9847 \\
\hline$\alpha_{\text {free }} /^{\circ}$ & 2 & 2 & 2 & 2 \\
\hline$\alpha_{\text {tun }} /{ }^{\circ}$ & 2 & 2 & 2 & 2 \\
\hline$K_{\alpha}$ & 1 & 1 & 1 & 1 \\
\hline$K_{a}$ & 0,9413 & 0,9649 & 0,9776 & 0,9847 \\
\hline
\end{tabular}

Table 2 Numerically obtained correction parameters, $\alpha=6^{\circ}, M=0,15$

\begin{tabular}{|c|c|c|c|c|}
\hline & $h=3$ & $h=4$ & $h=5$ & $h=6$ \\
\hline$C_{L \text { free }}$ & 0,7145 & 0,7145 & 0,7145 & 0,7145 \\
\hline$C_{L \text { tun }}$ & 0,7565 & 0,7385 & 0,7302 & 0,7245 \\
\hline$K_{C_{L}}$ & 0,9445 & 0,9675 & 0,9785 & 0,9862 \\
\hline$\alpha_{\text {free }} /{ }^{\circ}$ & 6 & 6 & 6 & 6 \\
\hline$\alpha_{\text {tun }} /{ }^{\circ}$ & 6 & 6 & 6 & 6 \\
\hline$K_{\alpha}$ & 1 & 1 & 1 & 1 \\
\hline$K_{a}$ & 0,9445 & 0,9675 & 0,9785 & 0,9862 \\
\hline
\end{tabular}

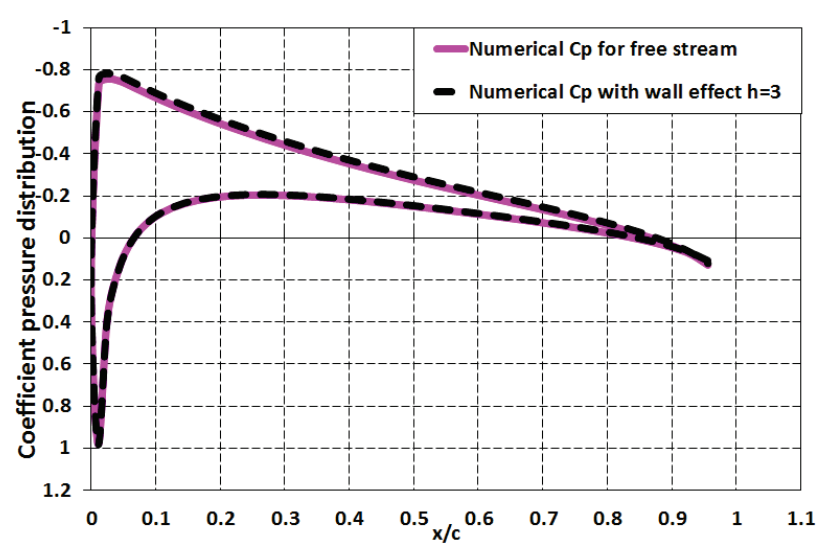

Figure 6 Numerical $C_{p}$ for free stream and with wind tunnel wall effect, for $h=3, \alpha=2^{\circ}, M=0,15$

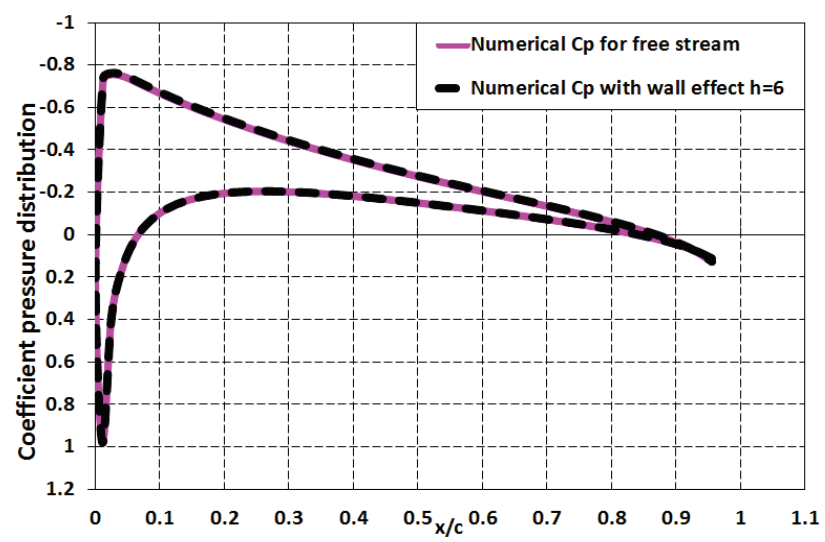

Figure 7 Numerical $C_{p}$ for free stream and with wind tunnel wall effect, for $h=6, \alpha=2^{\circ}, M=0,15$ 
Numerically obtained free stream values are slightly larger, because the applied calculations are based on the inviscid flow model, which inherently overestimates lift, due to the lack of boundary layer influence. On the other hand, the same model is applied both for the free stream and wind tunnel calculations; since pressure coefficients are subtracted, this shortcoming of inviscid calculation model vanishes.

The classical lift coefficient and angle of attack corrections, based on Abbott, Doenhoff and Stivers [12], and Pope \& Harper [13], have been calculated for the purpose of the comparisons (see Tabs. 3 and 4). In case of classical methods, the same values of correction parameters practically apply for both angles of attack.

Table 3 Analytical corrections: Abbot, Doenhoff and Stivers

\begin{tabular}{|c|c|c|c|c|}
\hline & $h=3$ & $h=4$ & $h=5$ & $h=6$ \\
\hline$K_{C_{L}}$ & 0,9657 & 0,9807 & 0,9876 & 0,9914 \\
\hline$K_{\alpha}$ & 1,0228 & 1,0128 & 1,0082 & 1,0057 \\
\hline$K_{a}$ & 0,9441 & 0,9682 & 0,9796 & 0,9858 \\
\hline
\end{tabular}

Table 4 Analytical corrections: Pope \& Harper

\begin{tabular}{|c|c|c|c|c|}
\hline & $h=3$ & $h=4$ & $h=5$ & $h=6$ \\
\hline$K_{C_{L}}$ & 0,9635 & 0,9790 & 0,9863 & 0,9903 \\
\hline$K_{\alpha}$ & 1,0229 & 1,0128 & 1,0082 & 1,0057 \\
\hline$K_{a}$ & 0,9419 & 0,9667 & 0,9782 & 0,9846 \\
\hline
\end{tabular}

Numerically obtained values are compared with these methods in Tab. 5.

Table 5 Lift curve slope correction factor by different methods

\begin{tabular}{|l|c|c|c|c|}
\hline$K_{a}$ & $h=3$ & $h=4$ & $h=5$ & $h=6$ \\
\hline Numerical $\alpha=2^{\circ}$ & 0,9413 & 0,9649 & 0,9776 & 0,9847 \\
\hline Numerical $\alpha=6^{\circ}$ & 0,9445 & 0,9675 & 0,9785 & 0,9862 \\
\hline Abbott, Doen. \& Stivers & 0,9441 & 0,9682 & 0,9796 & 0,9858 \\
\hline Pope \& Harper & 0,9419 & 0,9667 & 0,9782 & 0,9846 \\
\hline
\end{tabular}

Numerically obtained values of the lift curve slope correction factors show very good agreement with those obtained analytically, with small differences considering the two analysed angles of attack. By here presented method, the moment coefficient corrections can readily be obtained as well. On the other hand, since the analysed airfoil is symmetrical, values of quarter chord moment coefficient $C_{M 1 / 4}$ are very small, and they were not considered for the verification purposes.

Once again, it should be noted that these corrections apply for solid walls case only. Here applied model can be used for the corrections of measurements at higher subsonic Mach numbers as well, including lower transonic domain. The future work will be extended to the simulations of the ventilated walls, for example by adding the series of sinks on the upper and lower wind tunnel walls, which will simulate the outflow. Calibrating their strengths with respect to the existing wind tunnel measurements, corrections can be determined using the same logic as described in this paper.

\section{Conclusion}

A linear vortex strength panel method has been developed for the evaluation of wall interference corrections. The model (in this paper - airfoil NACA 0012) is represented by $N$ vortex segments in the test section, and they are mirrored by a sufficient number of their symmetric images with respect to the ceiling and the floor of the test section. The pressure distribution about the airfoil was calculated for free stream and in the test section. The difference in pressure coefficient $\Delta c_{p_{i}}$ between free-stream numerical solution and numerical solution with walls should then be subtracted from the pressure coefficient distribution measured in the wind tunnel, at the corresponding points. Pressure distribution obtained this way is integrated to obtain lift coefficient, which represents the free stream value, for the same nominal angle of attack and Mach number as in the wind tunnel. Using this algorithm, corrections are not applied directly to the lift coefficient and angle of attack, as in most classical methods, but to pressure coefficient distribution.

The verification of here presented calculation method has been performed by comparing numerically obtained lift curve slope corrections with those obtained by two well-known classical methods, and very good agreements have been obtained for several typical test cases. Here presented method readily calculates the quarter-chord moment corrections from the numerically determined solutions as well, but since symmetrical airfoil has been considered (with near-zero moment values), these values were not considered for verification purposes in this paper.

The application of the linear vortex strength paneling makes this method very resource and time efficient, and suitable for routine corrections of two-dimensional wind tunnel measurements. In future work, this method will be extended to the modeling of ventilated tunnel walls effects, while the basic concept of correction applications will be preserved.

\section{References}

[1] Ganzer, U. Adaptable wind tunnel walls for 2-D and 3-D model tests. // $12^{\text {th }}$ Congress of the international council of the aeronautical sciences ICAS / Munich Germany, 1980. Proceedings, pp. 808-816.

[2] Meyer, O.; Blume, S.; Nitsche, W. Experimental investigations on the Adaptation accuracy of adaptive slots in Wind tunnel test section walls. // $23^{\text {rd }}$ Congress of the international council of the aeronautical sciences ICAS / Toronto Canada, 2002. Proceedings, pp. 372.1-372.10.

[3] Sawada, H. Wind tunnel wall interference in a test section with ventilated walls. // $12^{\text {th }}$ Congress of the international council of the aeronautical sciences ICAS / Munich Germany, 1980. Proceedings, pp. 823-836.

[4] Mokry, M.; Ohman, L. H. Application of the fast Fourier transform to two-dimensional wind tunnel wall interference. // Journal of Aircraft. 17, 6(1980), pp. 402408. DOI: $10.2514 / 3.44666$

[5] Kupper, A. Wall correction method with measured boundary conditions for low speed wind tunnel. // paper 13 in AGARD CP-535, July 1994, pp. 13.1-13.10. 
[6] Mokry, M.; Digney, J. R.; Poole, R. J. D. Doublet-panel method for half-model wind-tunnel corrections. // Journal of Aircraft. 24, 5(1987), pp. 322-327. DOI: 10.2514/3.45448

[7] Beutner, T. J.; Celik, Z. Z.; Roberts, L. Determination of solid/Porous wall boundary conditions from wind tunnel data for computational fluid dynamics Codes. // paper 16 in AGARD CP-535, July 1994, pp. 16.1-16.19

[8] Ashill, P. R.; Weeks, D. J. A method for determining wallinterference corrections in solid wall tunnels from measurements of static pressure at the walls. // AGARDCP-335, May 1982, pp. 1.1 -1.12.

[9] Holt, D. R.; Hunt, B. The use of panel methods for the evaluation of subsonic wall interference. // Paper 2 in AGARD CP-335, May 1982, pp. 2.1-2.16

[10] Horstein, B. J. C.; Veldhuis, L. L. M. A New Hybrid Method to Correct for Wind Tunnel Wall- and Support Interference On-line. // International Journal of Research and Scientific Innovation. 3, 10(2009), pp. 501-508.

[11] Sheldahl, R. E.; Klimas, P. C. Aerodynamic Characteristics of Seven Symmetrical Airfoil Sections through 180-Degree Angle of Attack for Use in Aerodynamic Analysis of Vertical Axis Wind Turbines. // Sandia National Laboratories Energy Report: SAND80-2114; 1981

[12] Abbott, I. H.; von Doenhoff, A. E.; Stivers, Jr. L. S Summary of Airfoil Data. // NACA Report No. 824. 1933.

[13] Pope, A.; Harper, J. J. Low Speed Wind Tunnel Testing, John Wiley \& Sons, Inc., New York, 1966.

\section{Authors' addresses}

\section{Sc. Taha Ahmed Abdullah, Ph.D. student}

University of Mosul

Engineering College

Mosul, Iraq

+381616051488

E-mail: Tahatahamir99@yahoo.com

Dr. sc. Zlatko Petrović, Full Professor

University of Belgrade

Faculty of Mechanical Engineering

Kraljice Marije 16

11000 Belgrade, Serbia

\section{Dr. sc. Zoran Stefanović, Full Professor}

University of Belgrade

Faculty of Mechanical Engineering

Kraljice Marije 16

11000 Belgrade, Serbia

Dr. sc. Ivan Kostić, Associate Professor

University of Belgrade

Faculty of Mechanical Engineering

Kraljice Marije 16

11000 Belgrade, Serbia

Dr. sc. Jovan Isaković

Tehnikum Taurunum,

College of Applied Engineering Studies

Nade Dimić 4

11080 Zemun, Serbia 